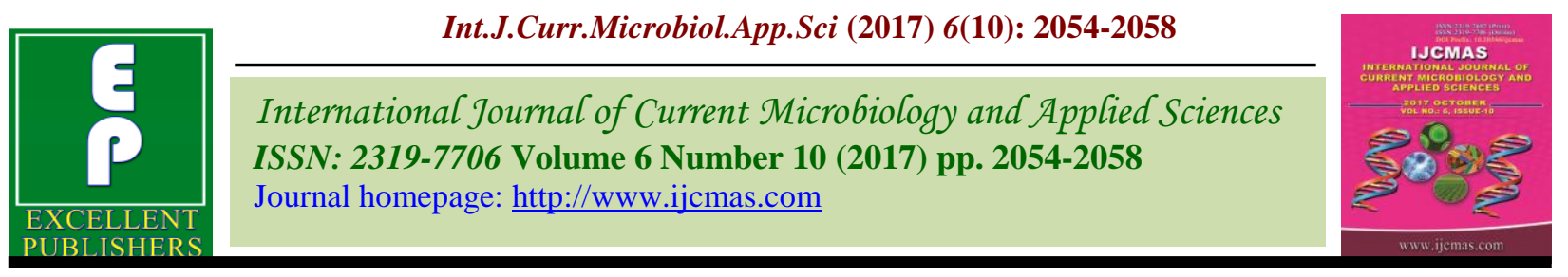

Original Research Article

https://doi.org/10.20546/ijcmas.2017.610.244

\title{
Dengue NS1 Antigen for Early Detection of Dengue Infection
}

\author{
J.V. Sathish, Mita D. Wadekar* and C. Pooja \\ Department of Microbiology, Chamarajanagar Institute of Medical Sciences, \\ Chamarajanagar, Karnataka, India \\ *Corresponding author
}

\begin{tabular}{|c|c|}
\hline & A B S T RA C T \\
\hline & \multirow{5}{*}{$\begin{array}{l}\text { Dengue is a mosquito-borne viral disease affecting tropical and subtropical regions of the } \\
\text { world. Symptoms may range from a mild undifferentiated febrile illness to dengue fever } \\
\text { (DF) and dengue haemorrhagic fever (DHF), a potentially life threatening disease. } \\
\text { Detection of non-structural antigen (NS1 Ag) may help in the early diagnosis and } \\
\text { treatment of dengue. Aim of the study is to detect dengue infection by NS1 Ag detection } \\
\text { and also to know its prevalence. A retrospective study was carried out in a tertiary-care } \\
\text { hospital in Chamarajanagar, Karnataka, India. The serum samples from } 787 \text { suspected } \\
\text { dengue cases which included patients of all age group and from both gender, were } \\
\text { subjected to dengue NS1 antigen detection by microwell enzyme-linked immunosorbent } \\
\text { assay (ELISA). Of } 787 \text { serum samples tested, } 286 \text { ( } 36.34 \%) \text { samples were positive for NS } 1 \\
\text { antigen. Maximum number of positive cases were in age groups of } 0-18 \text { years } 70 \text { ( } 24.48 \%) \\
\text { followed by } 19-45 \text { years } 69 \text { ( } 24.12 \% \text { ) with no significant difference between males } 64 \\
\text { ( } 54.70 \%) \text { and females } 53(45.30 \%) \text {. Prevalence of dengue } 36.34 \% \text { is high in our locality. } \\
\text { So a prevention strategy has to be taken. NS1 Ag detection has a significant role in early } \\
\text { diagnosis of dengue fever. Hence, it is recommended to do this test for early diagnosis and } \\
\text { treatment. }\end{array}$} \\
\hline $\begin{array}{l}\text { Ke y w o r d s } \\
\text { Dengue fever, } \\
\text { NS1 antigen, } \\
\text { Early detection. }\end{array}$ & \\
\hline Article Info & \\
\hline $\begin{array}{l}\text { Accepted: } \\
\text { 17 September } 2017 \\
\text { Available Online: } \\
\text { 10 October } 2017\end{array}$ & \\
\hline & \\
\hline
\end{tabular}

\section{Introduction}

Dengue virus infection has emerged as a notable public health problem in recent decades in term of the mortality and morbidity associated with it (Neralwar et al., 2015). It is the most common arboviral illness in humans (Amol Hartalkar et al., 2015). Dengue (DEN) virus belongs to the genus Flaviviruses, and consists of four serotypes: serotype 1 (DEN-1), serotype 2 (DEN-2), serotype 3 (DEN-3), and serotype 4 (DEN-4) (Aditi Garg et al., 2015). Infection to one serotype confers immunity only to that particular infecting serotype. Subsequent infection with one of the three remaining serotypes results in immune-enhanced disease in the form of severe hemorrhagic fever or dengue shock syndrome (Purimitla Usha Rani et al., 2017). Worldwide, an estimated 2.5 billion people are at risk of infection. It is estimated that more than 50 million infections occur each year, of which 500,000 hospitalizations are of dengue haemorrhagic fever, mainly among children, with the case fatality rate exceeding 5\% in some areas (Prakash Babaliche et al., 2015). Dengue is known in India since 1940s, but the disease is very limited in its spread. Dengue is becoming rampant in many states of southern 
India. As of now, no specific treatments or vaccines are available against the disease ( $R$. Chandran et al., 2015). Dengue viruses are transmitted to humans by Aedes aegypti mosquitoes and cause a wide range of symptoms, from unapparent or mild disease (dengue fever) to a severe hemorrhagic form (dengue hemorrhagic fever and dengue shock syndrome) (Philippe Dussart et al., 2006).

Diagnosis of acute dengue infection using clinical signs and symptoms is complicated by the wide range of possibilities for differential diagnosis, and therefore, laboratory assays are normally relied upon to make a diagnosis (Stuart D. Blacksell et al., 2012). Current diagnostic methods are often unable to recognize emerging epidemics in a timely manner or at a reasonable cost, drastically reducing the efficacy of control measures (Kovi Bessoff et al., 2008).

Detection of the dengue virus by virus isolation or by nucleic acid detection methods are considered as confirmatory tests for confirming the diagnosis of dengue infection. However, due to the need for advanced laboratory facilities these two methods may not be suitable for routine diagnosis of dengue virus infection early in the disease in resource poor communities (Paranavitane et al., 2014). Serological diagnosis offers many advantages including more flexible schedules for testing, lower cost, and more widely available reagents. But, cross-reactivity between other flaviviruses and "original antigenic sin" complicate specific diagnosis of secondary flavivirus infections (Kovi Bessoff et al., 2008).

Non-structural 1 (NS1) protein, which is approximately $45 \mathrm{kDa}$ in molecular weight, is secreted from dengue virus infected cells. Dengue NS1 antigen is an important diagnostic biomarker found circulating in patient blood samples (Wei Ru Wong et al.,
2016). The NS1 antigen is found together with endothelium, free or soluble in the sera of patients, from one day before the onset of symptoms and can be detected at least up to five days after the onset of symptoms, allowing for an early diagnosis (Bisordi et al., 2011). An enzyme-linked immunosorbent assay, specific to dengue virus type 1 nonstructural protein NS1, has been developed for detection of dengue NS1 antigen during the acute phase of disease in patients experiencing primary and secondary infections (Kumarasamy et al., 2007). In the absence of a vaccine, dengue prevention is focused upon controlling mosquito vectors (Natalia V. Voge et al., 2013). Controlling dengue infections is challenging because it requires not only effective control of vectors responsible for transmitting the virus but also accurate and rapid diagnosis (Fauziah $\mathrm{Md}$ Kassim et al., 2011).

\section{Materials and Methods}

A retrospective study was conducted at Chamarajanagar Institute of Medical Sciences, Chamarajanagar. The age, gender and results of dengue NS1 Ag ELISA test were collected from the laboratory registers. The data were entered into Excel for analysis. Permission was obtained from the institution. As the study was based on secondary data, there were no ethical issues.

With aseptic precautions, blood samples were collected from clinically suspected dengue cases. The serum was separated by centrifugation of the whole blood sample and if delay in testing, stored in the refrigerator at $-20^{\circ} \mathrm{C}$. NS1 antigen is detected by using Qualisa, a microwell enzyme immunoassay for dengue NS1 from Qualpro diagnostics (A division of Tulip Diagnostics (P) Ltd., phase II C, Verna Industrial Estate, Verna, Goa, India). The tests were carried out following the manufacturer instruction. 


\section{Results and Discussion}

A total of 787 dengue suspected serum samples were tested, of which 286 (36.34\%) samples were positive. Maximum number of cases were from age groups $0-18$ years 148 $(51.75 \%)$ and $19-45$ years $121(42.31 \%)$ followed by > 45 years group 17(05.94\%), which is very less. There was no significant difference between males $140(48.95 \%)$ and females 146 (51.05\%) (Tables 1 and 2).

Dengue virus infection most commonly affects tropical and subtropical regions of the world. Epidemics of dengue infection are showing an increasing trend in recent years (Ashwini Manoor Anand et al., 2016). With the escalating incidence of dengue infections and the absence of vaccines for the prevention of this disease, early diagnostic confirmation of dengue virus infections in patients is needed, as it allows for timely clinical intervention, etiologic investigations, and disease control. Hence, diagnosis of dengue disease during the acute phase should be a priority for patients and for public health reasons (Seok Mui Wang et al., 2010).

The study done by Paranavitane et al., (2014), found that platelet counts were lower in those who were NS1 antigen positive at the time of admission, but this was not significant. However, interestingly serum NS1 antigen levels significantly correlated with a serum interleukin (IL)-10 levels which are suggested as a possible marker of severe clinical disease. Currently, most laboratory dengue diagnosis is achieved by DENV isolation, RNA detection, ELISA for anti-DENV IgM and $\operatorname{IgG}$ antibodies and non-structural protein 1 (NS1) (Sundaram et al., 2016).

Apart from these traditional tests, latest advances such as use of biosensors are helpful in diagnosis (Pawar R et al., 2015). Inspite of availability of current diagnostic tools, there is a need for reliable and dependable tools that are relatively easy to use and that do not require highly skilled personnel or costly equipment (Meng Ling Moi et al., 2013).

Table.1 Prevalence of dengue cases

\begin{tabular}{|c|c|}
\hline Total no. of samples tested & No. of positive samples NO. (\%) \\
\hline 787 & $286(36.34)$ \\
\hline
\end{tabular}

Table.2 Age and gender wise distribution of dengue cases

\begin{tabular}{|c|c|c|c|}
\hline \multirow{2}{*}{$\begin{array}{c}\text { Age } \\
\text { (years) }\end{array}$} & $\begin{array}{c}\text { No. of positive } \\
\text { samples } \\
\text { NO. }(\%)\end{array}$ & \multicolumn{2}{|c|}{ Gender } \\
\cline { 3 - 4 } & $\begin{array}{c}\text { Males } \\
\text { NO. (\%) }\end{array}$ & $\begin{array}{c}\text { Females } \\
\text { NO. }(\%)\end{array}$ \\
\hline $\mathbf{0 - 1 8}$ & $148(51.75)$ & $78(27.27)$ & $70(24.48)$ \\
\hline $\mathbf{1 9}-\mathbf{4 5}$ & $121(42.31)$ & $52(18.18)$ & $69(24.12)$ \\
\hline$>\mathbf{4 5}$ & $17(05.94)$ & $10(03.50)$ & $07(02.45)$ \\
\hline Total & $\mathbf{2 8 6}(\mathbf{1 0 0})$ & $\mathbf{1 4 0}(\mathbf{4 8 . 9 5})$ & $\mathbf{1 4 6 ( 5 1 . 0 5 )}$ \\
\hline
\end{tabular}

Kulkarni RD et al., reported $40.6 \%$ positivity for any one of the dengue markers (IgM, IgG and NS1 antigen) by immune chromatography (Poongodi Lakshmi et al., 2014). In present study, dengue was detected in $36.34 \%$ which is significant. Out of 286 seropositive patients, $140(48.95 \%)$ were males and 146 $(51.05 \%)$ were females. The most affected age group was 0-18 years $148(51.75 \%)$ and $19-45$ years $121(42.31 \%)$ followed by $>45$ 
years group 17(05.94\%). NS1 Ag circulates uniformly in all serotypes of dengue virus and at high level during the first few days of illness (Syed Irfan Ahmed et al., 2010).

Its levels range from 0.004 to $2 \mu \mathrm{g} / \mathrm{ml}$ in acute phase serum, to only $0.004 \mu \mathrm{g} / \mathrm{ml}$ or less in convalescent-phase serum samples (Ashwini Manoor Anand et al., 2016). Along with the virus and viral RNA, it is detectable before the appearance of $\operatorname{IgM}$ and $\mathrm{IgG}$ antibodies in first infections and also before $\operatorname{IgM}$ in subsequent infections (Jacqueline Gosink. 2014). Enzyme-linked immunosorbent assay (ELISA) was developed to detect this viral protein (NS1 Ag). This assay has become a sensitive, specific test and is relatively inexpensive as compared to molecular diagnostics assays (Shamala, 2015). But here it is important to understand that, NS1 antigen detection assay has an advantage of detecting infection very early, however it disappears early also and is of little use in the early convalescence phase when $\operatorname{IgM}$ is useful (Pramod S. Manthalkar et al., 2017). Also, these serological tests are unable to distinguish the serotype of dengue virus causing the infection. Polymerase chain reaction (PCR) is fast becoming the method of choice for the rapid detection of dengue viruses, especially in reference and research laboratories. With the recent advances in realtime PCR, several methods have been developed using this versatile tool that enables rapid detection, serotype identification, as well as viral RNA quantitation (Kwoon-Yong Pok et al., 2010).

Dengue was detected in $36.34 \%$ which is significant and hence necessary efforts have to be taken for its prevention. NS1 Ag detection by microwell ELISA, which has high sensitivity and specificity, is very helpful in early diagnosis of dengue fever. It is recommended to do this test in all suspected dengue cases for early diagnosis and initiation of necessary treatment.

\section{References}

Aditi Garg, Ravindranath Gangane, Asharani S, Sharanabasava. 2015. Seroprevalence of Dengue in North Karnataka. Journal of Medical Science and Clinical Research, 3(6): 6192-6198.

Amol Hartalkar, Sheetal Hartalkar, Makarand Wani, Arvind Yadav. 2015. Dengue NS1 Antigen - for Early Detection of Dengue Virus Infection. WIMJOURNAL, 2(1): 1115.

Ashwini Manoor Anand, Sujatha Sistla, Rahul Dhodapkar, Abdoul Hamide, Niranjan Biswal, Badrinath Srinivasan. 2016. Evaluation of NS1 Antigen Detection for Early Diagnosis of Dengue in a Tertiary Hospital in Southern India. Journal of Clinical and Diagnostic Research, 10(4): DC01-DC04.

Bisordi, I., et al., 2011. Evaluation of dengue NS1 antigen detection for diagnosis in public health laboratories, Sao Paulo State, 2009. Rev. Inst. Med. Trop. Sao Paulo, 53(6): 31520.

Chandran, R., and P. A. Azeez. 2015. Outbreak of dengue in Tamil Nadu, India. Current science, 109(1): 171-176.

Fauziah Md. Kassim, M Nur Izati, TAR TgRogayah, Y Mohd Apandi and Zainah Saat. 2011. Use of dengue NS1 antigen for early diagnosis of dengue virus infection. Southeast Asian J Trop Med Public Health, 42(3): 562-569.

Jacqueline Gosink, 2014. Early laboratory diagnosis of dengue infections. Medlab Magazine, 3:14-16.

Kovi Bessoff, Mark Delorey, Wellington Sun, and Elizabeth Hunsperger. 2008. Comparison of 2 Commercially Available Dengue NS1 Capture Enzyme-Linked Immunosorbant Assays for Diagnosis of Acute DENV Infection with a Single Clinical Sample. Clin. Vaccine Immunol., 1-25.

Kumarasamy, V., Chua S K, Hassan Z, Wahab A H A, Chem Y K, Mohamad M, Chua K B. 2007. Evaluating the sensitivity of a commercial dengue NS1 antigen capture ELISA for early diagnosis of acute dengue virus infection. Singapore Med J, 48(7): 669673. 
Kwoon-Yong Pok, Yee-Ling Lai, Joshua Sng, and Lee-Ching Ng. 2010. Evaluation of Nonstructural 1 Antigen Assays for the Diagnosis and Surveillance of Dengue in Singapore. Vector-borne and zoonotic diseases, 10(10): 1009-1016.

Meng Ling Moi, et al., 2013. Detection of Dengue Virus Nonstructural Protein 1 (NS1) by Using ELISA as a Useful Laboratory Diagnostic Method for Dengue Virus Infection of International Travelers. Journal of Travel Medicine, 20(3): 185-193.

Natalia V. Voge, Irma Sa'nchez-Vargas, Carol D. Blair, Lars Eisen, and Barry J. Beaty. 2013. Detection of Dengue Virus NS1 Antigen in Infected Aedes aegypti Using a Commercially Available Kit. Am. J. Trop. Med. Hyg., 88(2): 260-266.

Neralwar, A., Banjare B, Barapatre R. 2015. Detection of NS1 antigen, IgM antibody for the diagnosis of Dengue infection in patients with acute febrile illness. Int J Res Med Sci, 3:2826-30.

Paranavitane, et al., 2014. Dengue NS1 antigen as a marker of severe clinical disease. BMC Infectious Diseases, 14:570.

Pawar, R., Patravale V. 2015. Dengue Diagnosis: Challenges and Opportunities. Immunochem Immunopathol, 1(1): 105.

Philippe Dussart, et al., 2006. Evaluation of an Enzyme Immunoassay for Detection of Dengue Virus NS1 Antigen in Human Serum. Clinical and vaccine immunology, 13(11): 1185-1189.

Poongodi Lakshmi, S., N Palaniappan. 2014. Rapid immunochromatographic test to detect NS1antigen, Ig M and Ig G: An alternative to enzyme linked immunosorbent assay in diagnosis of dengue at primary care level. $\mathbf{J}$ Clin Biomed Sci, 4(4):353-56.

Prakash Babaliche, Darshan Doshi. 2015. Catching Dengue Early: Clinical Features and Laboratory Markers of Dengue Virus
Infection. Journal of the Association of Physicians of India, 63: 38-41.

Pramod S. Manthalkar, B.V. Peerapur. 2017. Utility of NS1 Antigen for Diagnosis of Dengue Virus Infection. Journal of Krishna Institute of Medical Sciences University, 6(1): 72-75.

Purimitla Usha Rani, Payala Vijayalakshmi. 2017. Serological Diagnostic Assays for Detection of NS1 Antigen, IgM and IgG Antibodies to Dengue Virus. International Journal of Infectious Diseases and Therapy, 2(1): 9-14.

Seok Mui Wang, and Shamala Devi Sekaran. 2010. Evaluation of a Commercial SD Dengue Virus NS1 Antigen Capture Enzyme-Linked Immunosorbent Assay Kit for Early Diagnosis of Dengue Virus Infection. Journal of Clinical Microbiology, 48(8): 2793-2797.

Shamala, D.S., 2015. Laboratory Diagnosis of Dengue: A Review. The International Medical Journal Malaysia, 14(1): 17-28.

Stuart D. Blacksell, et al., 2012. Comparison of Seven Commercial Antigen and Antibody Enzyme-Linked Immunosorbent Assays for Detection of Acute Dengue Infection. Clinical and Vaccine Immunology, 19(5): 804-810.

Sundaram, A.K., Lee CRR, Wu SJL. 2016. Review of Current Laboratory Diagnostics for Dengue Fever. Clin Res Infect Dis, 3(5): 1044.

Syed Irfan Ahmed, et al., 2010. NS1 Antigen and Immunoglobulin $\mathbf{M}$ detection in the Acute and Early Convalescent Stages of Dengue Fever. Journal of Rawalpindi Medical College (JRMC), 14(2):56-59.

Wei Ru Wong, Shamala Devi Sekaran, Faisal Rafiq Mahamd Adikan, Pierre Berini. 2016. Detection of dengue NS1 antigen using longrange surface plasmon waveguides. Biosensors and Bioelectronics, 78: 132-139.

\section{How to cite this article:}

Sathish, J.V., Mita D. Wadekar and Pooja, C. 2017. Dengue NS1 Antigen for Early Detection of Dengue Infection. Int.J.Curr.Microbiol.App.Sci. 6(10): 2054-2058. doi: https://doi.org/10.20546/ijcmas.2017.610.244 